\title{
LA REPRESENTACIÓN DE LAS MUJERES TRABAJADORAS EN LA PRENSA ESPAÑOLA
}

\author{
Florencia Rovetto Gonem \\ Universidad Nacional de Rosario (Santa Fe) \\ florencia.rovetto@gmail.com
}

Núria Simelio Solà

Universidad Autónoma de Barcelona

nuria.simelio.sola@uab.es

Recibido: 04-02-09

Aceptado: 20-02-09

\section{Resumen}

En este artículo presentamos los resultados de varias investigaciones sobre la representación del trabajo de las mujeres en la prensa realizadas por el Feminario Mujeres y Cultura de Masas de la UAB. Demostramos mediante el análisis de contenido que la prensa de información general no ha reflejado la incorporación de una gran cantidad de mujeres españolas e inmigrantes al mercado de trabajo durante los últimos 30 años. Consideramos que un mayor tratamiento informativo de estos cambios sociales podría incidir en la realidad vital de las lectoras y proporcionarles elementos para evaluar las políticas públicas destinadas prioritariamente a las mujeres.

Palabras clave: Mujeres, trabajo, prensa de información general.

\begin{abstract}
This article present the results of several researchers carried out by the group Women and Mass Culture Feminary from the UAB. We demonstrate through the content
\end{abstract}


analysis that the quality press avoids to properly inform about the incorporation of a great number of Spanish and immigrant women in the labor market in the last 30 years. We consider that a better informative treatment of these social changes could fall into the life reality of the women readers and provide them elements in order to evaluate the public policies addressed to women.

Key words: Women, work, quality press.

\section{Introducción}

En la actual fase de la economía global se cristaliza un proceso de acumulación capitalista que comienza a emerger en la década del setenta y que se caracteriza por el acelerado incremento de las transacciones que favorecen un poder y una autonomía sin precedentes del sector financiero. A su vez, en esta fase, los mercados laborales de los países centrales han experimentado importantes transformaciones debido al fuerte crecimiento del sector servicios, creando una oferta de puestos de trabajos no cualificados y precarios, ocupados en su mayoría por mujeres autóctonas e inmigrantes.

Teniendo en cuenta estos cambios, en nuestros estudios partimos de la hipótesis de que el empleo en España se ha transformado notablemente en los últimos treinta años, con la incorporación de una gran cantidad de mujeres españolas e inmigrantes al mercado de trabajo, pero sin embargo, la representación de este fenómeno no ha sido registrada fielmente por la prensa de información general.

Nos planteamos que un desproporcionado acceso a los niveles de representación de las mujeres (y de gran parte de la ciudadanía diversa y plural de distintas edades, procedencias y condiciones socioeconómicas) en los medios puede incidir sobre la capacidad de participación activa en los escenarios públicos, máxime si tenemos en cuenta que una de las principales funciones de los medios de comunicación, en la sociedad democrática moderna, es servir de instrumento para el acceso a 
conocimientos significativos que faciliten a la ciudadanía participar en la vida pública, intervenir políticamente y tomar decisiones de carácter individual y colectivo.

A su vez, consideramos que las transformaciones sociales que se producen en el área del trabajo, los nuevos modelos femeninos de acceso y promoción del empleo y las modificaciones legales promovidas por las políticas públicas, para garantizar la igualdad efectiva entre hombres y mujeres, no son suficientemente enfocadas en los textos periodísticos, y que un mayor tratamiento informativo de estos cambios podría incidir en la realidad vital de las lectoras y proporcionarles elementos para evaluar las políticas públicas destinadas prioritariamente a las mujeres.

Nuestras investigaciones se centran en la emisión y no en la recepción de los mensajes periodísticos por parte del público lector, y a su vez, sólo en ciertos aspectos de la emisión, aquellos que tienen que ver con la mujer y su relación con el mercado de trabajo, conscientes de que los discursos mediáticos son un factor importantísimo a la hora de elaborar estereotipos, representaciones e imaginarios dominantes.

\section{Mujer y trabajo. Un binomio que no ha dejado de transformarse}

Hacia la segunda mitad del siglo XX se destacan grandes cambios en materia de igualdad entre mujeres y hombres, tanto en España como en gran parte del mundo occidental. Sin duda, los movimientos feministas tuvieron un papel trascendental en dichos cambios. Pero al mismo tiempo fueron favorecidos por una dinámica política y económica novedosa y contradictoria que necesitó una renovación estructural de las relaciones entre mujeres y hombres, tanto en el ámbito privado como en el público.

El desarrollo de las fuerzas productivas en el período señalado generó una demanda de población cualificada que ha influido notablemente sobre la estimación social de la formación y el trabajo de las mujeres. Principios como el de "igualdad de oportunidades", presente en las Bases para una política educativa española del 
Ministerio de Educación y Ciencia en 1969, ratifican la creciente incorporación de la mujer a las aulas y el trabajo extra-doméstico.

Sin embargo, esta aparente liberación y "conquista de territorios" impulsada a principios de los años 70 desde el propio Estado venía a regular cambios en la estructura social que siguieron condicionados por el modelo dominante. Según la cita del Libro Blanco sobre la educación en España que recogen Ferrándiz y Verdú podemos inferir la verdadera intencionalidad de esta incorporación: "En la medida en que la educación es considerada como la palanca fundamental del progreso social y el desarrollo económico, sería una contradicción subestimar la inapreciable aportación que la mujer (preferiblemente una mujer culturalmente elevada) puede efectuar en este aspecto tan crucial como es la educación de los niños y puede afirmarse que - aún desde el punto de vista estrictamente económico, no digamos desde el punto de vista social - es en muchos casos notablemente superior la aportación al producto social que la mujer pudiera efectuar con su incorporación a las unidades económicas de producción" (Ferrándiz y Verdú, 2004: 186).

Con estos postulados se trató de favorecer la formación femenina para generar amas de casa y esposas cualificadas, pero sin cuestionar los roles preasignados ni fomentar una verdadera "igualdad de oportunidades" en todos los órdenes de la vida social.

Sin embargo, para que el sistema capitalista contara con mano de obra más barata y mejor cualificada, era imprescindible incorporar a las mujeres al mercado laboral. Esta es una de las principales razones por la cual, la tradicional "ama de casa" se fue incorporando gradualmente a las universidades, las fábricas y las oficinas, y pasó a ser un nuevo y numeroso sector consumidor de bienes y servicios que el propio mercado local generaba.

A lo largo del siglo pasado también se hicieron visibles las conquistas de los derechos políticos de las mujeres, que desde 1931 poseen la capacidad de elegir y ser elegidas en los comicios electorales. Sin embargo, el acceso a la esfera política de las mujeres y de gran parte de la población no goza de plenitud. Los principios de igualdad 
y libertad que están en la base de la construcción sociopolítica de las democracias modernas pueden ser puestos en cuestión, ya que los "pactos entre iguales" que otorgan el estatuto de ciudadanos de pleno derecho, siguen siendo hoy muy restringidos, y hacen que muchas mujeres, por falta de experiencia histórica, o simplemente por inferioridad numérica, no participan del debate, la discusión y la gestión racional-moderna en todas las esferas decisorias del espacio público (Simón Rodríguez, 1992: 31).

El término "ciudadano" parece no ser adjudicable a todas las personas por igual. Por su parte, tampoco la prensa de información general ha reflejado históricamente la universalidad de ese término. Según Simelio, en los últimos treinta años, la prensa española de información general: "adoptó un compromiso claro con la reforma política dirigida por las elites dominantes y la trasmitió a la opinión pública. Los diarios educaron y cohesionaron a las masas lectoras y las dotaron de referentes de identificación y cohesión social" (Simelio, 2006).

La representación de las mujeres y del resto de la población en la prensa, como sujetos activos de la vida social y política, como ciudadanas de pleno derecho para ocupar los espacios de decisión, no ha aumentado proporcionalmente a la incorporación de las mujeres a los espacios antes reservados a los varones.

Por otra parte, también en el terreno de la sexualidad y la familia se produjeron cambios trascendentales para las mujeres. Recordemos que el modelo de "familia extensa" previa a la Revolución Industrial fue una institución de derecho privado encargada de trasmitir el patrimonio, los oficios, el linaje y los apellidos, en la que el rol materno constituía un eje fundamental en la vida de la mujer, dedicada al sostenimiento de la unidad de producción económica y reproducción humana.

Con el paso del proceso de industrialización la estructura de "familia extensa" ha ido derivando en la de "familia nuclear", donde las mujeres vieron reforzado sus roles de máxima responsable emocional y afectiva del bienestar familiar, y al mismo tiempo como trasmisora de pautas, modelos y colaboradora en el sostenimiento económico del hogar. 
Más adelante, el derecho a la anticoncepción de uso femenino, también supuso una ruptura de la equivalencia mujer-madre y la conquista del derecho a una maternidad libre y opcional ${ }^{1}$.

Podemos decir que algunos aspectos del proceso emancipatorio, aunque incipientes, fueron avanzando según las mujeres hemos ido adquiriendo ciertos derechos fundamentales:

- El acceso a la educación ha permitido adquirir una identidad ideológica configuradora de libertad.

- La conquista del voto otorga la legitimidad y la ocupación de espacios de ciudadanía social ("lo público”).

- El acceso al mundo público, la entrada al mercado laboral y profesional, otorgan una identidad social.

- El control de la reproducción desvincula a la mujer de "lo natural" y le otorga libertad de decisión y deseo, junto con la posibilidad de creación de nuevos modelos familiares.

Llegadas aquí, nos preguntamos si estas transformación históricas de las relaciones cotidianas y políticas, que afectan a mujeres y hombres, se han plasmado con la misma intensidad que sus efectos tienen en la realidad, en el relato que los medios de comunicación construyen.

Como ya hemos señalado, es evidente que las mujeres y el resto de los hombres que no forman parte de las elites de poder, no se encuentran representados en el discurso informativo. Y esta forma de explicar la realidad, en lugar de fomentar el papel activo de la ciudadanía plural en el control democrático, reduce las posibilidades de intervención a unas minorías, exaltando y reproduciendo una forma de poder despótica desde el centro hacia la periferia.

\footnotetext{
${ }^{1}$ Llegamos así a nuevos modelos de familia, impensables hace menos de un siglo atrás: familias agregadas, familias monoparentales, o familias homoparentales.
} 
Aunque las conquistas en los distintos ordenes de la emancipación, conseguidas por las mujeres son muchas y de gran trascendencia para la vida de las personas, la situación general está todavía muy lejos de ser la ideal. El cambio de trabajo de las mujeres es una realidad incuestionable que ha marcado profundamente la evolución del mercado de trabajo español en el último cuarto del siglo XX hasta la actualidad. La participación de la mujer en la actividad laboral ha experimentado un crecimiento constante, pero con ciertas peculiaridades. La opción de muchas mujeres por el trabajo remunerado no ha conseguido remover los obstáculos para su participación igualitaria.

Por otra parte, estos profundos cambios que han afectado el nivel y la composición del empleo en España, han modificado también las relaciones entre mujeres y hombres. El estatuto socioeconómico de las mujeres se ha visto alterado al incrementarse de forma progresiva su participación en el mercado de trabajo, modificando consecuentemente otras situaciones, como el modelo de fecundidad, el modelo matrimonial y la propia organización familiar.

Además, uno de los rasgos más sobresalientes del mercado de trabajo español ha sido precisamente el fuerte incremento de la tasa de actividad femenina, que contrasta con el descenso de la tasa de actividad masculina (Frau Llinares, 2005: 217). Frente a la caída constante de la tasa de actividad masculina, la tasa de actividad femenina no ha dejado de crecer en los últimos treinta años.

Estas transformaciones a nivel de la participación laboral, también han generado estilos de vida diferentes que expresan una específica manera de vivir y de relacionarse entre mujeres y hombres. Cada vez surge con más fuerza una nueva forma de familia, en la que la mujer participa en el mercado laboral sin abandonar sus funciones de cuidadora y gestora del hogar, generalmente en solitario o con una débil participación de los hombres. A la redistribución de las responsabilidades financieras en la familia no ha seguido una redistribución de las responsabilidades domésticas.

No se ha superado aún la norma social tradicional que asigna a las mujeres como actividad prioritaria la responsabilidad doméstica, norma que convive con el 
derecho al empleo y a la carrera profesional que las mujeres hemos ido interiorizando. Por otra parte, quedan por resolverse muchas formas de discriminación en el trabajo que María José Frau resume de la siguiente manera: “las mujeres soportan mayores escollos para incorporarse al empleo; las mujeres suelen ocupar puestos periféricos y menos prestigiosos; las mujeres soportan una mayor precarización; y algunas de las acciones encaminadas para conciliar el trabajo fuera y dentro del hogar (como la jornada parcial) no hacen más que ampliar las desigualdades en el mercado laboral" (Frau Llinares, 2006: 227-249).

\section{La representación de las mujeres en la prensa}

En las últimas décadas se han realizado numerosas investigaciones sobre la representación de las imágenes de la mujer en los medios de comunicación. Podemos destacar la de Concha Fagoaga y Petra Secanella, de principios de los años 80, "Umbrales de presencia de las mujeres en prensa española", sobre prensa diaria "de élite" y "popular". Estas autoras señalan que los diarios presentan un mundo de imágenes masculinas, reafirmando que los periódicos están hechos por varones y para varones, y atribuyen el bajo porcentaje de referencias a mujeres, a que éstas no están presentes en las agendas de los diarios, no son portavoces de organismos burocráticos, no son enfocadas como fuentes de información y, en muchos casos, tampoco son consideradas como audiencia. Por último, advierten que esta situación acarrearía graves consecuencias y restricciones a la posibilidad de que las nuevas generaciones de mujeres encuentren referencias suficientes para sus objetos vitales y profesionales: “...los medios de comunicación están dando a conocer a los jóvenes en particular un mundo que ya no existe”; (...) "el poder y la política son conceptos de varones y los periodistas llevan esos conceptos a las páginas de sus periódicos”; (...) “restringiendo la posibilidad de que nuevas generaciones de mujeres encuentren en la prensa diaria 
referencias suficientes para sus objetivos vitales y profesionales" (Fagoaga, Secanella, 1984).

En otra investigación dirigida por Vicente Baca Lagos en el año 95 se hace un balance de las investigaciones realizadas en El País, sobre la imagen de la mujer en los medios de comunicación, y se concluye que "los medios de comunicación se ajustan tardíamente a los nuevos roles adoptados por las mujeres, si bien la publicidad moderniza la imagen de la mujer para atender a las necesidades derivadas de sus recientes roles”.

Otros estudios, provenientes del ámbito internacional que se ocupan del monitoreo global de los medios de comunicación son los sucesivos informes presentados por The Global Media Monitoring Project (GMMP), donde se analiza esta problemática en diferentes países del mundo y en todos los ámbitos de la comunicación social.

En el informe presentado en 1995 se observaron diferentes noticias de televisión, radio y periódicos, emitidas y publicadas un día ordinario, en más de 71 países y se demostró que la representación de la mujer está profundamente relacionada con el contexto económico y político de cada país ${ }^{2}$. Sin embargo, este hecho es un matiz que no modifica la tendencia general que reveló el informe del proyecto internacional, cuyos resultados se dieron a conocer en la Cuarta Conferencia Mundial de las Naciones Unidas sobre la Mujer en Pekín en 1995, dejando patente que la discriminación que sufre la mujer en los medios de comunicación de todo el mundo.

Si nos detenemos a reflexionar sobre la presencia de las mujeres en las noticias, se destaca fundamentalmente su ausencia como protagonistas, algo que se ha llegado a denominar "aniquilación simbólica" (Menéndez, 2003). Esto equivale a decir que la representación de las mujeres es desproporcionadamente inferior a su presencia en el

\footnotetext{
${ }^{2}$ The Global Media Monitoring Project - GMMP - (1995). Este proyecto está coordinado por la Asociación Mundial para la Comunicación cristina (WACC, por sus siglas en inglés), una organización internacional, no-gubernamental que promueve la comunicación para el cambio social. Los datos para el monitoreo 2005 fueron recogidos gracias a la colaboración de organizaciones de mujeres, incluyendo activistas del género y de los medios, grupos de base de la comunicación, académicos y estudiantes de la comunicación, profesionales de los medios, asociaciones de periodistas y redes de medios alternativos de diferentes países.
} 
mundo laboral y cultural. Actualmente, las mujeres constituyen al menos un $35 \%$ de la población que dispone empleo remunerado - sin tener en cuenta el empleo público o el trabajo en el hogar donde su representación es mucho más elevada -, y apenas son sujeto informativo en los periódicos de información diaria o en los informativos televisivos

A su vez, la representación, enfoque y tratamiento de las mujeres en las noticias es, a menudo, estereotipada, con particular énfasis sobre el aspecto físico y los vínculos familiares. Estas características de la representación femenina en las noticias tienen relación con la posición social, con las expectativas y valoraciones en torno a las mujeres y, de modo igualmente importante, con la propia percepción de si mismas que los medios contribuyen a formar.

Muchos de los estudios realizados sobre mujeres y medios de comunicación han puesto de manifiesto que la imagen de las mujeres que se trasmite desde la información, y aún más desde la publicidad, sigue anclada en los roles tradicionales, sin reflejar la realidad actual de unas mujeres que contribuyen activamente al proceso de desarrollo de la sociedad.

\section{Análisis de la representación de las mujeres y el trabajo en la prensa}

Se ha demostrado ampliamente, gracias a muchos trabajos realizados desde la perspectiva del género, y desde la crítica al androcentrismo, que el tratamiento informativo de la realidad que hacen la mayoría de los medios de comunicación actualmente, no sólo favorece los prejuicios sexistas, sino, lo que es más preocupante aún, construye un relato sesgado de la realidad, que da cuenta de una parte de la población, y por tanto, de una parte de la historia. Y una historia contada a medias no puede ser "toda" la Historia.

La línea de investigación abierta por Moreno Sardà en los años ochenta desde una perspectiva crítica al androcentrismo del discurso académico y de los medios de 
comunicación nos ha ayudado a revisar las teorías y también las prácticas periodísticas. Sus reflexiones acerca del sistema de valores dominantes basado en una particular concepción de lo humano en sentido genérico y universal (Moreno, 1996, 1998), nos han permitido re-pensar en las categorías epistemológicas que utilizamos para investigar los medios y la representación simbólica que estos hacen de la realidad.

Los medios de comunicación pueden ser tomados como fuentes documentales para explicar la Historia, pero teniendo en cuenta que representan una determinada realidad, muchas veces sesgada y restringida a un sector de la población. ¿Cuáles son las motivaciones y la intencionalidad de este procedimiento restrictivo de la información? Por tanto, ¿qué entra y qué queda fuera del relato de la realidad que hacen los medios y por qué estos procedimientos se ponen en marcha? Son algunas de las preguntas que guían esta investigación.

Recordemos como apunta Moreno Sardá que la mirada androcéntrica de la prensa se ha acentuado, a la vez que se ha deshumanizado: "se ha desplazado de los varones identificados con nombre y apellido, a las instituciones desde las que se gestiona el poder político, económico, cultural, etc., que aparecen ahora como sujetos agentes y protagonistas de la Historia cotidiana, como si los seres humanos no las hicieran funcionar y todavía más, como si fueran inapelables a gran parte de la ciudadanía" (Moreno Sardà, 2004). En consecuencia, este desplazamiento está provocando un distanciamiento de las decisiones políticas de la mayoría de la población cuya capacidad de intervención como protagonistas aparece mucho más reducida.

Estos rasgos de las sociedades democráticas actuales, caracterizadas por la ausencia de "todos" los protagonistas que hacen la Historia deberían ser, al menos, inquietantes para los gestores políticos, y sobre todo para aquellos que en sus programas electorales plantean la necesidad de la participación ciudadana como pilar de la construcción democrática.

Michèle Mattelart, ya en los años 80, llamaba la atención sobre el sesgo que se produce en la cultura de masas. Para ella, las industrias culturales presentan el trabajo de la mujer como un sucedáneo, como una actividad compensatoria cuya única legitimidad 
depende precisamente de ser un elemento secundario en su vida, ofreciendo la dependencia de las mujeres al rol familiar como única invariable realidad, como la “esencia" misma del sujeto femenino (Mattelart, 1982).

Lo que señala esta autora plantea la dicotomía que los mass media consagran entre trabajo primario y secundario, juzgando incompatible el realizado fuera de casa, con la maternidad y el trabajo en el hogar. Y apunta que las páginas de revistas y diarios no nos plantean la distribución solidaria de las tareas domésticas como solución sino que recurren a la mistificación de la maternidad como oficio principal, convirtiendo a la mujer en la mayor responsable de los fracasos del sistema familiar.

Por otra parte, Érica Flahaut analiza la imagen que se recoge de las mujeres en los medios de comunicación a partir de los años setenta, y le llama la atención que la prensa, desde ese momento, comience a hacer alusión continua a las "mujeres solas". La investigadora comenta que los retratos femeninos que pintan los periodistas siguen reflejando los discursos tradicionalistas del siglo XIX: "La puesta en escena de la soledad femenina no es más que una forma, apenas diferente, de poner de relieve el precio que las mujeres han de pagar por su emancipación; es una advertencia y un medio de oponer una imagen triste para combatir el ideal de independencia propuesto por los movimientos feministas" (Flahaut, 2000).

Para esta autora, el discurso mediático les dice a las mujeres que son libres, que han conseguido la igualdad, pero que ahora son infelices: padecen agotamiento, infertilidad, soledad, nuevas enfermedades, etc.

Pero toda esta situación no se da aislada de unas condiciones económicas y sociopolíticas determinadas. En este sentido, se llega a un punto en el que hay que considerar el desajuste y las modificaciones del papel masculino a partir de los arquetipos simbólico mediáticos: "el hombre está aceptando críticamente unos comportamientos cada vez más canalizados hacia unos intereses económicos y políticos que sitúan la competitividad como su núcleo ideológico" (Abril, 2001: 39).

De ahí, señala Abril, que la mujer sea considerada un elemento competidor en contra del cual se está enfocando una desviación de la violencia y de la agresividad 
generalizada. Y este rebrote o permanencia de actitudes misóginas, proceden de una situación de crisis global de la sociedad post industrializada: "tal proceso va forjando paulatinamente un deterioro de la humanización y posibilita la aparición de fenómenos de agresividad que casi leemos diariamente en cualquier periódico" (Abril, 2001).

Desde esta peculiar manera de enfocar la realidad que hacen los medios, se favorece la creación en nuestro imaginario de todo un serial de tópicos, de unos perfiles ideológicos de gran calado y persistencia que resultan difíciles de contrastar o modificar, dejando un pozo de informaciones inconscientes en nuestra memoria colectiva que nos hacen comparar, asociar, valorar y jerarquizar los contenidos informativos, positiva o negativamente, según las distintas actividades humanas, los grupos sociales o las relaciones entre sexos.

La falta de poder de las mujeres en los medios de comunicación es una situación que se reproduce en todas partes, con mayor o menor significación cultural. En Francia, la Asociación de Periodistas de París llega a plantear que las mujeres, aún siendo grandes lectoras - superando ampliamente el nivel de lectura de los hombres -, apenas leen los periódicos. Y esto sucede porque la realidad que se les ofrece no coincide con su experiencia vital, ni con su forma de entender y ver el mundo (Tancart, 1996).

Para cambiar esta situación el periodismo tiene la responsabilidad social de ofrecer una imagen distinta, que deje de reforzar la marginalidad del discurso publico de las mujeres desde las páginas de los diarios y las revistas, desde las pantallas de televisión y desde el resto de los soportes de los denominados medios de comunicación social.

Debemos ser capaces de lo que refiere con "hacer visible el conjunto de seres humanos que hacen la historia", o en palabras de Ferro "descubrir lo latente detrás de lo aparente, lo visible, detrás de lo invisible” (Moreno, 1998), ya que la visión que las personas tenemos de la historia contemporánea y del contexto histórico está mediatizada por una supuesta objetividad que, en realidad, es parcial, "realza unos aspectos y deja en la penumbra otros" entre los que se encuentra el trabajo de las mujeres. 
Unas pautas para construir los mensajes ofreciendo una mirada sobre la realidad que se corresponda con la vida de todas las mujeres y los hombres, lograría además que la ciudadanía global encuentre en los medios de comunicación el reflejo de su trayectoria vital, haciendo más atractivo el contenido informativo que se ofrece.

En nuestras investigaciones, para analizar la representación de las mujeres en la prensa aplicamos la herramienta de análisis de contenido Test ADSH para evaluar la Amplitud, Diversidad y Sensibilidad Humana de la mirada informativa (Moreno; Rovetto; Buitrago, 2007), que parte de la pregunta ¿de quién hablan las noticias?, para identificar ¿qué mujeres de distintas edades, procedencias y condiciones son considerados protagonista en las noticias, y en qué actuaciones y escenarios son enfocadas? También nos interrogamos por la autoría de la información, esto es, ¿quién enfoca y con qué fuentes construye la información?, para evaluar el tratamiento que se ofrece de las mujeres y de los modelos femeninos de trabajo.

Partimos del diagnóstico y los resultados de la investigación realizada por el equipo Feminario Mujeres y Cultura de Masas de la Universidad Autónoma de Barcelona en el proyecto $\mathrm{I}+\mathrm{D}+\mathrm{I}$ "La representación de las relaciones entre mujeres y hombres y del recambio generacional en la prensa, de 1974-2004" (Moreno et. al., 2004).

En la memoria final de dicha investigación se destaca que "las diferencias en la representación simbólica de mujeres y hombres en los diferentes medios de comunicación responden a hábitos de pensamiento androcéntrico (y no sólo de género) que afectan el enfoque y el tratamiento de la realidad social".

En esta línea, se suman las conclusiones de Núria Simelio, sobre el análisis de la prensa de información general durante la transición española. Sus resultados ponen de manifiesto con claridad que el enfoque mayoritario de la mirada informativa en la prensa considerada seria se dirige a las elites políticas con un tratamiento prioritario y positivo, como los protagonistas, primero en el franquismo, y después en la transición y la monarquía constitucional, y que aparecen en los periódicos como gestores del cambio político y social: “El conjunto de los periódicos analizados muestra una considerable 
presencia de varones que desarrollan una actividad política y ostentan una posición jerárquica. Las instituciones gubernamentales permanecen como el principal escenario de la agenda periodística y sus protagonistas e instituciones son ciertamente los actores más prominentes" (Simelio, 2006).

\subsection{Análisis de la representación del trabajo de las mujeres durante la transición política española}

Los resultados de la investigación examinan la presencia de las representaciones sociales en cuatro periódicos de información general durante el periodo que va de 1974 a 1984. Se han analizado todas las unidades comunicativas de 11 ejemplares completos a partir de 121 variables. Las unidades de análisis totales son 3.298 repartidas entre El País (425), La Vanguardia (970), El Correo Español/El Pueblo Vasco (794) y ABC (1190). El total de datos registrados es de 399.058.

Como podemos ver en la siguiente tabla las mujeres identificadas reciben una menor atención en los periódicos analizados:

Tabla 1. Evolución de mujeres y hombres identificados con nombre y/o apellidos (número de referencias y porcentaje de superficie)

\begin{tabular}{|l|c|c|c|c|c|c|}
\hline & \multicolumn{2}{|c|}{1974} & \multicolumn{2}{c|}{1979} & \multicolumn{2}{c|}{1984} \\
\hline Mujeres identificadas & Número & Superficie & Número & Superficie & Número & Superficie \\
\hline ABC & 10 & $6.1 \%$ & 4 & $2.8 \%$ & 14 & $6.4 \%$ \\
\hline El Correo Español & 3 & $1.4 \%$ & 10 & $2.5 \%$ & 2 & $1.7 \%$ \\
\hline El País & & & 3 & $2.0 \%$ & 4 & $2.4 \%$ \\
\hline La Vanguardia & 7 & $1.5 \%$ & 2 & $0.6 \%$ & 7 & $4.1 \%$ \\
\hline Hombres identificados & & & & & & \\
\hline ABC & 75 & $42.5 \%$ & 72 & $34.8 \%$ & 66 & $28 \%$ \\
\hline El Correo Español & 42 & $29.8 \%$ & 59 & $32.2 \%$ & 37 & $27.7 \%$ \\
\hline El País & & & 36 & $31.4 \%$ & 51 & $32.5 \%$ \\
\hline La Vanguardia & 77 & $27.4 \%$ & 54 & $28.7 \%$ & 55 & $28 \%$ \\
\hline
\end{tabular}

Base: Unidades Redaccionales que enfocan un solo protagonista. 
Como ponen de manifiesto los datos de esta tabla, las mujeres merecen muy poca atención en todos los diarios, tanto en número de UR como en \% de SR. La abundancia de nombres de varones adultos contrasta con la escasez de nombres de mujeres, como si a lo largo de esos años no se hubieran incorporado a las mismas profesiones, como si la actividad pública continuara siendo un reducto exclusivamente viril. Las mujeres identificadas constituyen un repertorio muy reducido en el enfoque de los diarios analizados, pero precisamente por esto, es significativo que nos detengamos a analizar quienes son estas mujeres.

Según las tablas, el ejemplar que enfoca menos mujeres tanto en número como en porcentaje de espacio es La Vanguardia de 1979, con tres mujeres que sólo ocupan el $0,6 \%$ de la superficie. Dos forman parte de un colectivo de varias personalidades entre las que se encuentran MariCruz Soriano, el doctor Puigvert, Rosa María Mateo y José Luís Balbín. La otra mujer es enfocada como víctima Piedad Luna, empleada de limpieza, ha sido apuñalada con heridas graves en la azotea del inmueble donde trabajaba. Se supone que el agresor se encontraba alli escondido con otros propósitos que le desbarató inconscientemente la infeliz mujer.

En los ejemplares de 1974 y 1984 La Vanguardia enfoca principalmente mujeres relevantes por ser deportistas, artistas, víctimas, o tener un elevado estatus social. En 1974, de las 7 mujeres enfocadas, cinco son actrices, una deportista, y Doña Laura Laverdós Sinón que dio a luz una niña. Entre las actrices se encuentra Charlotte Dalgle de treinta y un años de edad, que ha tardado un año en conseguir un visado para entrar en Rusia y así poder casarse con un artista ruso al cual conoció en Leningrado en 1968.

En el ejemplar de La Vanguardia de 1984 se enfoca a 8 mujeres, dos son deportistas, cuatro artistas, y dos aparecen en la sección de sociedad. Por otro lado, encontramos a una sola mujer con poder político, Margaret Tatcher, presidenta de gobierno.

$A B C$ es el diario analizado que enfoca a un mayor número de mujeres identificadas. Sin embargo, la tipología de mujeres que llaman la atención al diario es la 
misma que en las otras cabeceras. En 1974 de las 10 protagonistas que aparecen en 9 UR se encuentra una deportista, una miss, una reina, Isabel de Inglaterra, cuatro artistas, una escritora, una detenida por posesión de droga, Maria Das Grazas Silva de la que se advierte que es súbdita brasileña, con 21 años y de profesión maniquí y una “señora de”, Señora de Yllera (don Guillermo) de soltera Mauca Díaz de Bustamante ha dado a luz a un niño, primero de sus hijos, que recibió el nombre de Guillermo.

En 1979, ABC enfoca 5 protagonistas mujeres. La protagonista que ocupa más espacio es Patricia Hearst (sonriente abandona la prisión), que aparece en las primeras páginas y en la sección de sucesos. Esta protagonista es enfocada por quebrantar la ley, si bien, a diferencia de 1974, en que también hay una delincuente, aquí se resalta su origen familiar acomodado. Las otras tres, son una presentadora de televisión, una actriz, y la única empresaria de la muestra que contesta una encuesta sobre si le da miedo salir a la calle a causa del terrorismo. Por último, se enfoca sarcásticamente a una mujer finlandesa de 60 años, muerta en brazos de un latin lover.

El $A B C$ de 1984 es el que más mujeres enfoca de toda la muestra, con 14 mujeres y el $6,4 \%$ de la superficie. Siete tienen una profesión relacionada con el espectáculo; una actriz de cine, Marilyn, una actriz de teatro, Lola Herrera, una azafata del programa de televisión 1,2,3, una soprano, dos modelos y un personaje de ficción, Elena Francis. Tres son enfocadas como "señoras de" a causa de haber dado a luz. Al igual que en los otros ejemplares, también se enfoca una deportista Tina Lillack de la que se dice explícitamente que es de mirada levemente miope y tiene unas piernas largas como una carretera de "middle west", y una delincuente, $\mathrm{M}^{\mathrm{a}}$ Teresa Mestre. Finalmente, encontramos Ronit Sova, enfocada por su condición de mujer y su posición jerárquica en una institución: ocupa el puesto de instructor de los paracaidistas judios,

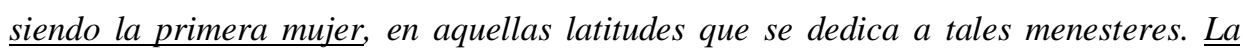
sonriente sargento mayor contabiliza ya doscientos cuarenta saltos. También se destaca que tiene 23 años y es judía.

El ejemplar de 1974 El Correo Español/ El Pueblo Vasco enfoca a tres mujeres identificadas con nombre y apellidos: una princesa heredera que ha cumplido 36 años, 
una historiadora condecorada con la orden británica del mérito, galardón que solamente habían recibido tres mujeres hasta ese momento, que premia la labor de aquellos súbditos que se distinguieron en el ejército, la marina, las ciencias, el arte o la literatura, y una deportista, record mundial de natación.

En 1979, amplia el enfoque a diez mujeres, seis de ellas dedicadas al espectáculo: cuatro cantantes, una pianista y una actriz que se divorcia. También se enfoca a dos mujeres con el estereotipo de víctima: una viuda de un policía asesinado, y una mujer de 21 años que consigue una indemnización por una negligencia médica. Y dos delincuentes: una refugiada vasca miembro de ETA, y Patricia Hearst que sale en libertad después de una condena por robar a mano armada en un banco.

En 1984, El Correo Español sólo enfoca dos mujeres: una expresa y exmiembro de ETA, acogida a medidas de gracia, objeto de insultos personales y llamadas anónimas; y al personaje de ficción Elena Francis, consejera sentimental y marca comercial.

El País sólo incluye 3 mujeres (2\%) como protagonistas en el ejemplar de 1979 y $4(2,4 \%)$ en el de 1984 . Por tanto, enfoca a muy pocas mujeres y cuando lo hace pone de manifiesto imágenes preconcebidas del tipo de mujeres que llaman la atención del diario. Tanto en 1979 como en 1984 encontramos una mujer que representa la niña rica que cae en la delincuencia: Patricia Hearst, multimillonaria saliendo de la prisión después de su relación con un grupo revolucionario, y Peach de Rohan, en la contraportada, una princesa suiza, expulsada de un internado por fumar marihuana. También enfoca a deportistas: Andrea Matay, atleta húngara y Tina Lillack campeona del mundo de jabalina. Otro modelo es el de la artista, Mia Farrow, que solicita el divorcio, y Eulalia Solé, pianista. Finalmente, sólo encontramos una mujer anónima identificada con nombre y apellido, que aparece en la contraportada, Dolores Fernández Feijoo, artesana.

Resulta significativo que en los ejemplares analizados de las cuatro cabeceras se enfoque a las mujeres principalmente cuando realizan actividades artísticas y deportivas, como víctimas, delincuentes o "señoras de". Son mostradas como agentes 
pasivos y receptores de acciones muchas veces negativas, o en las que no suelen ser enfocados los protagonistas masculinos, como tener hijos. Además, se hacen calificaciones sobre sus características personales, como la simpatía o la belleza. No aparecen como representantes públicas de las diferentes actividades sociales, excepto Margaret Tatcher, y se las relega a la vida privada.

Por tanto, las mujeres identificadas con nombre y apellidos no tienen acceso ni presencia en los ejemplares analizados, ya que en el conjunto de ejemplares analizados representan menos del $5 \%$ de las protagonistas de las informaciones. Si tenemos en cuenta que las mujeres como colectivo representan algo más del 50\% de la población, los resultados muestran que la prensa de información general no ha reflejado las transformaciones que se sucedieron durante la transición y la democracia que significaron la recuperación del pleno derecho de ciudadanía para las mujeres. El periodo de la transición es básico en términos de transformaciones sociales entre hombres y mujeres, ya que durante la dictadura, no estaba ni siquiera reconocida la igualdad legal entre sexos, que no se estableció hasta 1978 con la formulación de la Constitución Española. En esta etapa se despenalizan los anticonceptivos, el divorcio, el adulterio y en algunos aspectos el aborto que significan cambios trascendentales para la vida de la población española. Desde finales de 1974 se constituyeron grupos de mujeres en todo el Estado y en 1975, coincidiendo con el año Internacional de la Mujer, se realizaron las Primeras Jornadas de Liberación de la Mujer en Madrid, con la asistencia de 500.000 mujeres de todo el Estado. Los datos del análisis permiten concluir que la prensa, al resistirse a dar cuenta de estos cambios, actuó como freno a pesar de que la sociedad y la legalidad mejoraran la situación general y potenciaran las transformaciones sociales.

Paralelamente, esta posición conservadora respecto a las mujeres se pone de manifiesto en la voluntad de continuar atribuyendo un protagonismo exclusivo a los varones, a pesar de que su posición cambiara. Así, la tabla 1 muestra que, a diferencia de las mujeres identificadas, los varones identificados con nombres y apellidos merecen mucha más atención en todas las cabeceras. Destaca $A B C$ con 75 UR que 
ocupan 42 '5 \% de la SR en 1974, aunque se va reduciendo pasando a 34'8 \% de la SR y a $28^{\prime} 0$ \% de la SR en 1979 y 1984 respectivamente, y a 72 y 66 UR en los mismos años.

\subsection{Análisis de la representación del trabajo de las mujeres inmigrantes}

Los resultados del análisis cualitativo sobre la representación del trabajo de las mujeres inmigrantes en una muestra compuesta por el diario $A B C$ y la revista femenina Lecturas, publicados en las tres últimas décadas $(1984,1994,2004)$ nos permitieron confirmar y concluir que la migración femenina y el trabajo de las mujeres inmigrantes está invisibilizado y distorsionado en dichas publicaciones.

En el diario $A B C$, las trabajadoras inmigrantes son presentadas como colectivos anónimos, enfocadas en espacios marginales, pacientes o padecientes de circunstancias individuales y del contexto, sin capacidad de acción o decisión. Por otra parte, en las páginas de la revista Lecturas, las escasas menciones acerca del país de origen o el lugar de nacimiento que presentan las protagonistas aportan información de carácter positivo, ("simpática gaditana"; "guapa dominicana"). Estas designaciones también son valoradas positivamente en los anuncios clasificados del diario $A B C$, con designaciones que destacan sus atributos personales y su procedencia geográfica. (rumanas y rusitas calientes; guapa brasileña, extranjeras exuberantes).

El tratamiento de las mujeres extranjeras varía según miremos unas páginas u otras del diario analizado. Las noticias sobre la inmigración asocian a las trabajadoras con la ilegalidad, los trabajos mal remunerados y la explotación, promoviendo una visión distorsionada de la integración de mujeres extranjeras en la vida laboral española.

Estos ejemplos del diario $A B C$ muestran a trabajadoras inmigrantes como protagonistas sólo en las imágenes de dos informaciones en cuyos titulares se hace referencia a situaciones conflictivas: "España limitará la entrada de los trabajadores del Este para evitar un efecto llamada" (página 18); y "Más de 5.000 niños y niñas españoles están atrapados hoy en redes de prostitución” (página 44). 
Comprobamos que el tratamiento de la "prostitución" es desigualmente atendido en las informaciones y en la publicidad que presenta $A B C$. Esto pone de manifiesto una escasa y negativa presencia en las informaciones, y una muy alta y positiva presencia en los anuncios clasificados por palabras en relación a la oferta de servicios sexuales por parte de las mujeres inmigrantes. Mientras que las informaciones las presentan vinculadas a hechos conflictivos (turismo sexual, ilegalidad, mafias de proxenetas) omitiendo referencias sobre el contexto histórico, social y económico, en la publicidad, se aporta una visión no conflictiva de este trabajo, donde predomina la representación de transacciones económicas, relaciones interpersonales y atributos individuales que positivizan los servicios ofrecidos.

A su vez, las informaciones que hacen referencia al trabajo de las mujeres inmigrantes en el diario $A B C$ priorizan los portavoces gubernamentales e institucionales como principales fuentes para la elaboración de dichas noticias, omitiendo la propia voz de las mujeres implicadas en los acontecimientos noticiosos.

\section{Conclusiones}

Podemos afirmar que en el conjunto de textos periodísticos analizados, se da una ausencia total de referencias a la necesidad de generar un debate social sobre la situación del empleo de las mujeres: la precariedad, la conciliación, la doble jornada de trabajo y la igualdad de oportunidades, que incluya a diferentes protagonistas individuales y colectivos y a las propias involucradas.

Estos resultados ponen en evidencia que se hace necesario introducir cambios en las rutinas de la mirada informativa, para ampliar y diversificar el enfoque e incorporar al debate público a una ciudadanía cada vez más plural con condiciones de vida y expectativas diversas.

La misión democrática del periodismo no es una idea moderna. El concepto de creación de "participación ciudadana" ha impregnado todas las declaraciones 
importantes y argumentos que ubican a la prensa, sus empresarios, profesionales y lectores, en el centro del debate.

Actualmente, damos por sentado que los medios de comunicación son una de las patas de la democracia, y a su vez, no creemos que exista la capacidad de intervenir socialmente sin estar informados, pero también sin ser los protagonistas de la información, es decir, sin estar en el escenario donde se toman las decisiones que rigen nuestra vida en sociedad.

Esperamos que los resultados de estas investigaciones puedan ser útiles, no sólo en los ámbitos académicos o educativos sino, incluso, para los mismos los medios de comunicación, como parte de asumir cada día más cabalmente su responsabilidad social en la consolidación democrática del conjunto de la ciudadanía, capaz de intervenir sociablemente. $\mathrm{Y}$ esperamos también, contribuir a generar prácticas de visibilización del trabajo de las mujeres que nos permitan encontrar posibles soluciones colectivas para hacer informaciones excéntricas, diversas, plurales y atractivas que enfoquen los cambios protagonizados por las mujeres y legitimen su inclusión en los escenarios de poder. 


\section{Bibliografía}

- Abril, N. (2001): “Modelos hegemónicos y 'otras' realidades en la prensa diaria: Recreación informativa del "héroe" y la "víctima" en el relato de actualidad". En Muñoz, B. (coord.) Medios de comunicación, mujeres y cambio cultural. Madrid: Dirección general de la Mujer de la Comunidad de Madrid, pp. 125-180.

- Beltran, M. (1991): La realidad social. Madrid: Editorial Tecnos.

- Eco, U. (1983): "Viatgem na irrealidade quotidiana". [Traducción propia] http://www.alohacriticon.com/viajeliterario/article1023.html [Consultada: 29 de agosto de 2006].

- Fagoaga, C. y Secanella, P. M. (1984): Umbrales de presencia de la mujer en la prensa española. Madrid: Instituto de la Mujer.

- Ferrándiz, A., Verdu, V. (2004): Noviazgo y matrimonio en la vida española 19742004. Madrid: Taurus.

- Flahaut, E. (2000): "La triste imagen de la mujer sola". En Bard, C. (et al) Un siglo de antifeminismo. Madrid: Biblioteca Nueva.

- Frau, M. J. (2005): "Mujer y mercado de trabajo". En: Asparkía. Investigaciones Feministas, № 16, pp. 215-257.

- Gil, E. (1998): La era de las lectoras. El cambio cultural de las mujeres españolas. Madrid: Instituto de la Mujer.

- Harris, M. (1980): Cultural Materialism: The Struggle for a Science of Culture. New York: Random House.

- Kobach B. y Rosentiel, T. (2003): Los elementos de periodismo. Madrid: Ediciones El País.

- Martín Serrano, M. (1982): Los profesionales en la sociedad capitalista. Madrid: Taurus.

- McBride, S. (1988): Un sólo mundo, voces múltiples. Madrid: FCE / UNESCO. 
- McQuail, D. (1985): Introducción a la teoría de la comunicación de masas. Barcelona: Paidós.

- Moreno, A. (1986): El arquetipo Viril protagonista de la Historia. Ejercicios de lectura no-androcéntrica. Barcelona: Ediciones La Sal.

- Moreno, A. (1998): La mirada informativa. Barcelona: Bosch.

- Moreno, A. (dir.), (2004): La representación de las relaciones entre mujeres y hombres y del recambio generacional en la prensa, de 1974 a 2004. Bellaterra: UAB. Proyecto I+D+I No7/01.

- Rovetto, F. (2006): La representación del Trabajo de las mujeres en la prensa. Bellaterra: Trabajo de Doctorado, presentado en el Departamento de Periodismo, Universidad Autónoma de Barcelona.

- Santos, F. (1995): Periodistas. Madrid: Temas de hoy.

- Simelio, N. (2006): Prensa de información general durante la transición política española (1974-1984): pervivencias y cambios de la representación de las relaciones sociales. Bellaterra: Servicio de Publicaciones de la Universitat Autònoma de Barcelona.

- Simón, M. H. (1992): “Olimpia de Gouges: Del sueño del pacto a la guillotina”. En: Canalobre, Revista del Instituto de Cultura "JuanGil-Albert”, № 23/24, pp.34-98.

- Tancart, M. (1996): Cherchez la femme: photografhie de la place des femmes dans les médias. París: Association des femmes jornalistes. 